\title{
Effects of D-region RF heating studied with the Sodankylä Ion Chemistry model
}

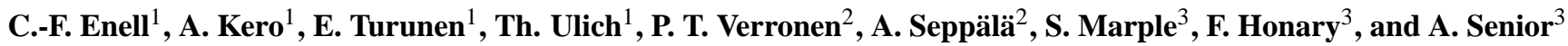 \\ ${ }^{1}$ Sodankylä Geophysical Observatory, Finland \\ ${ }^{2}$ Finnish Meteorological Institute, Helsinki, Finland \\ ${ }^{3}$ Lancaster University, UK
}

Received: 29 October 2004 - Revised: 11 January 2005 - Accepted: 12 January 2005 - Published: 27 July 2005

Part of Special Issue "Atmospheric studies by optical methods"

\begin{abstract}
The upper mesosphere and lower thermosphere, or ionospheric D region, is an atmospheric layer which is difficult to access experimentally. A useful method that also has a large potential for further studies is artificial heating of electrons by means of powerful radio transmitters. Here we estimate the effect of D-region heating for a few typical cases of high electron density - daylight, typical auroral electron precipitation, and a solar proton event - by coupling a model of RF electron heating to the Sodankylä Ion Chemistry (SIC) model. The predicted effects are among others an increase in the ratio of the concentration of negative ions to that of free electrons, and an increase in the absorption of cosmic noise as measured by riometers. For the model runs presented in this paper we have calculated the absorption for the frequency $(38.2 \mathrm{MHz})$ of the IRIS imaging riometer in Kilpisjärvi, Finland, as observing the ionosphere above the EISCAT Heater in Troms $\varnothing$, Norway. The predicted enhancements of the absorption are $0.2-0.8 \mathrm{~dB}$, an effect which is clearly detectable.
\end{abstract}

Keywords. Ionosphere (Active experiments; Ion chemistry and composition; Wave propagation)

\section{Introduction}

Artificial heating of ionospheric free electrons by means of powerful HF transmitters is a well established experimental method. Elevated electron temperatures give rise to several effects, such as perturbations of the electron density and an enhanced formation rate of negative ions which is important in the D region. Incoherent scatter radars (ISRs), riometers and optical instruments are applied for remote sensing of the effects. Stubbe (1996) has reviewed many of the experiments undertaken with the European Incoherent Scatter Scientific Association (EISCAT) Heater, which is collocated with the

Correspondence to: C.-F. Enell

(carl-fredrik.enell@sgo.fi)
UHF and VHF ISR transmitters close to Troms $\varnothing$ in Norway and thus a unique facility of its kind.

Many recent experiments with the EISCAT heater have focused on radio-induced optical emissions from the $\mathrm{F}$ region (Brändström et al., 1999; Kosch et al., 2002a,b). In these applications, the system is configured to transmit in the o-mode circular polarisation, in order to avoid losses by D-region absorption. On the other hand, transmitting in the $\mathrm{x}$-mode during adequate background conditions (daytime and/or strong particle precipitation), the experiments can be optimised for D-region studies.

There are, in fact, several classes of such dedicated Dregion experiments. Artificial Periodic Irregularities (API) is a combined heating and diagnostic radar experiment (Belikovich et al., 1986), which has been successfully demonstrated with the EISCAT heater (Rietveld et al., 1996). A power-stepping D-region heating experiment, combined with ISR observations, gives another interesting possibility to study the negative ion region (Mathews and Bekeny, 1978; Turunen, 1996) but this has not yet been experimentally tested. Other experiments involving D-region effects include the generation of extremely low frequency (ELF) pulsations (Pashin et al., 1995) and modulation of polar mesospheric summer echoes (Chilson et al., 2000). The latter is a process involving attachment of electrons to aerosols and thus somewhat similar to the negative ion related experiments suggested here.

The modulation of riometer absorption during heating experiments under different conditions of energetic particle precipitation has been estimated by Pashin et al. (2003), whose results, i.e. an increase by $0.2-0.5 \mathrm{~dB}$ of the cosmic noise absorption at $38.2 \mathrm{MHz}$, agree well with the results of this work. Minami et al. (1999) have possibly detected this effect experimentally, but do not state any quantitative results, except for the altitude of maximal heater wave absorption. 
Table 1. The electron temperature dependent recombination and attachment reactions in SIC. For sources, see Turunen et al. (1996).

\begin{tabular}{ll}
\hline Reaction & Rate coefficient $\left[\mathrm{m}^{-3} \mathrm{~s}^{-1}\right]$ \\
\hline $\mathrm{O}_{2}+\mathrm{N}_{2}+\mathrm{e} \longrightarrow \mathrm{O}_{2}^{-}+\mathrm{N}_{2}$ & $10^{-25} \times \frac{300}{T_{\mathrm{e}}} \times \exp \left(-600 / T_{\mathrm{e}}\right)$ \\
$\mathrm{O}_{3}+\mathrm{e} \longrightarrow \mathrm{O}^{-}+\mathrm{O}_{2}$ & $9.1 \cdot 10^{-6} \times\left(\frac{300}{T_{\mathrm{e}}}\right)^{-1.46}$ \\
$2 \mathrm{O}_{2}+\mathrm{e} \longrightarrow \mathrm{O}_{2}^{-}+\mathrm{O}_{2}$ & $4 \cdot 10^{-24} \times \exp \left(-193 / T_{\mathrm{e}}\right)$ \\
$\mathrm{O}^{-}+\mathrm{NO} \longrightarrow \mathrm{NO}_{2}+\mathrm{e}$ & $3.1 \cdot 10^{-4} \times\left(\frac{300}{T_{\mathrm{e}}}\right)^{0.83}$ \\
$\mathrm{O}^{+}+\mathrm{e} \longrightarrow \mathrm{O}$ & $4.0 \cdot 10^{-6} \times\left(\frac{300}{T_{\mathrm{e}}}\right)^{0.7}$ \\
$\mathrm{O}_{2}^{+}+\mathrm{e} \longrightarrow 2 \mathrm{O}$ & $1.6 \cdot 10^{-1} \times\left(\frac{300}{T_{\mathrm{e}}}\right)^{0.625}$ \\
$\mathrm{O}_{4}^{+}+\mathrm{e} \longrightarrow 2 \mathrm{O}_{2}$ & $4.2 \times\left(\frac{300}{T_{\mathrm{e}}}\right)^{0.5}$ \\
$\mathrm{~N}_{2}^{+}+\mathrm{e} \longrightarrow \mathrm{N}+\mathrm{N}\left({ }^{2} \mathrm{D}\right)$ & $1.8 \cdot 10^{-1} \times\left(\frac{300}{T_{\mathrm{e}}}\right)^{0.39}$ \\
$\mathrm{NO}^{+}+\mathrm{e} \longrightarrow \mathrm{N}+\mathrm{O}$ & $4.2 \cdot 10^{-1} \times\left(\frac{300}{T_{\mathrm{e}}}\right)^{0.85}$ \\
$\mathrm{NO}^{+}\left(\mathrm{N}_{2}\right)+e \longrightarrow \mathrm{NO}+\mathrm{N}_{2}$ & $1.4 \times\left(\frac{300}{T_{\mathrm{e}}}\right)^{0.4}$ \\
$\mathrm{H}^{+}\left(\mathrm{H}_{2} \mathrm{O}\right)+\mathrm{e} \longrightarrow \mathrm{H}+\mathrm{H}_{2} \mathrm{O}$ & $6.3 \cdot 10^{-1} \times\left(\frac{300}{T_{\mathrm{e}}}\right)^{0.5}$ \\
$\mathrm{H}^{+}\left(\mathrm{H}_{2} \mathrm{O}\right)_{2}+\mathrm{e} \longrightarrow \mathrm{H}+2 \mathrm{H}_{2} \mathrm{O}$ & $2.5 \times\left(\frac{300}{T_{\mathrm{e}}}\right)^{0.1}$ \\
$\mathrm{H}^{+}\left(\mathrm{H}_{2} \mathrm{O}\right)_{3}+\mathrm{e} \longrightarrow \mathrm{H}+3 \mathrm{H}_{2} \mathrm{O}$ & $3.0 \times\left(\frac{300}{T_{\mathrm{e}}}\right)^{0.1}$ \\
\hline
\end{tabular}

\section{The SIC model}

The $\mathrm{D}$ region is rather a challenge to study, partly due to the difficulty of obtaining experimental data and partly, from the point of view of modelling, due to the fact that it is necessary to take into account complex coupled reactions of neutral components, positive ions and negative ions. The latter has not been feasible until rather recently, due to the computer power needed for model implementations. Many models, such as the widely used 2-D UBAIM model (Kazil et al., 2003), do not include coupling of neutral and ion reactions. Our approach, on the other hand, is to run a comprehensive model of ion-neutral reactions, using a simple numerical approach and restricting ourselves to one dimension.

The Sodankylä Ion Chemistry model (SIC) was originally developed as a steady-state box model of ion-ion reactions (Turunen et al., 1996). Later, SIC was extended into a 1-D model of coupled ion and neutral reactions. Detailed descriptions of changes and additions have been published by Verronen (2001) and Verronen et al. (2002). We therefore only briefly summarise the most important features of the current version of SIC here.

The current version of SIC models up to 36 positive and 29 negative atomic, molecular and cluster ions, as well as up to 13 neutral components, in the altitude range $20-150 \mathrm{~km}$. The remaining neutral components have fixed concentrations given by the MSISE-90 model (Hedin, 1991) and tables in Shimazaki (1984). Normally, SIC is forwarded in inter- vals of 5 to $15 \mathrm{~min}$, using a reaction matrix, where the rates of nearly 400 reactions are taken into account. Vertical transport of neutral species is calculated between the intervals, except for $\mathrm{O}\left({ }^{1} \mathrm{D}\right)$ and $\mathrm{N}\left({ }^{2} \mathrm{D}\right)$, due to the fact that their chemical lifetimes are much shorter than the transport time scale. The one-dimensional approach of SIC is fully sufficient for the present study of local heating effects, since an air parcel cannot be heated for a time interval longer than its traversal of the heater beam.

The D-region mean free path is sufficiently short so as to justify the assumption that ion, electron and neutral temperatures are equal during undisturbed conditions, i.e. whenever the heater is off. For the present study, however, the electron temperature $T_{\mathrm{e}}$ must be separated from the ion/neutral temperature $T$ when calculating the reaction rates of electron attachment and ion-electron recombination, since these will be affected by the heating. The reaction rate coefficients affected by this separation are listed in Table 1 . We assume that the use of these same reaction rate coefficients is justifiable since the electron temperature will not deviate from the neutral temperature by more than one order of magnitude (see Rees, 1989). During the subsequent SIC runs, the electron temperature was either set equal to the neutral temperature (henceforth referred to as "background runs") or calculated by the electron heating model described in Sect. 3.1 ("heating runs").

Assuming overall neutrality, we can calculate the electron density from the model results as

$N_{\mathrm{e}}=N_{\mathrm{p}}-N_{\mathrm{n}}$,

where $N_{\mathrm{p}}$ and $N_{\mathrm{n}}$ are the total concentrations of positive and negative ions, respectively.

\section{Estimating the effects of RF heating}

\subsection{The electron heating model}

The electron temperature is calculated by a parallel-layer model described by Kero et al. (2000). The principle follows Belova et al. (1995) and is shown schematically in Fig. 1. For each model layer $i$, the dissipation $Q_{i}$ of radio wave energy by electron heating is calculated from the imaginary part of the refractive index $n$ according to

$Q=-2 \omega_{\mathrm{H}} \operatorname{Im}(n) \frac{I_{i}+I_{\mathrm{refl}}}{c}\left[\mathrm{Wm}^{-3}\right]$,

where $\omega_{\mathrm{H}}$ is the angular frequency of the heater wave, $I_{i}$ and $I_{\text {refl }}$ are the incident and reflected irradiances at layer $i$, and the complex refractive index $n$ is calculated by the AppletonLassen equation for a given electron density and magnetic field. The incident irradiance $I_{0}$ at the bottom layer at altitude $h_{0}$ (altitudes are for a given SIC model run, i.e. at a maximum $20-150 \mathrm{~km}$ in $1-\mathrm{km}$ steps) is assumed to be the effective radiated power (ERP) of the transmitter divided by 


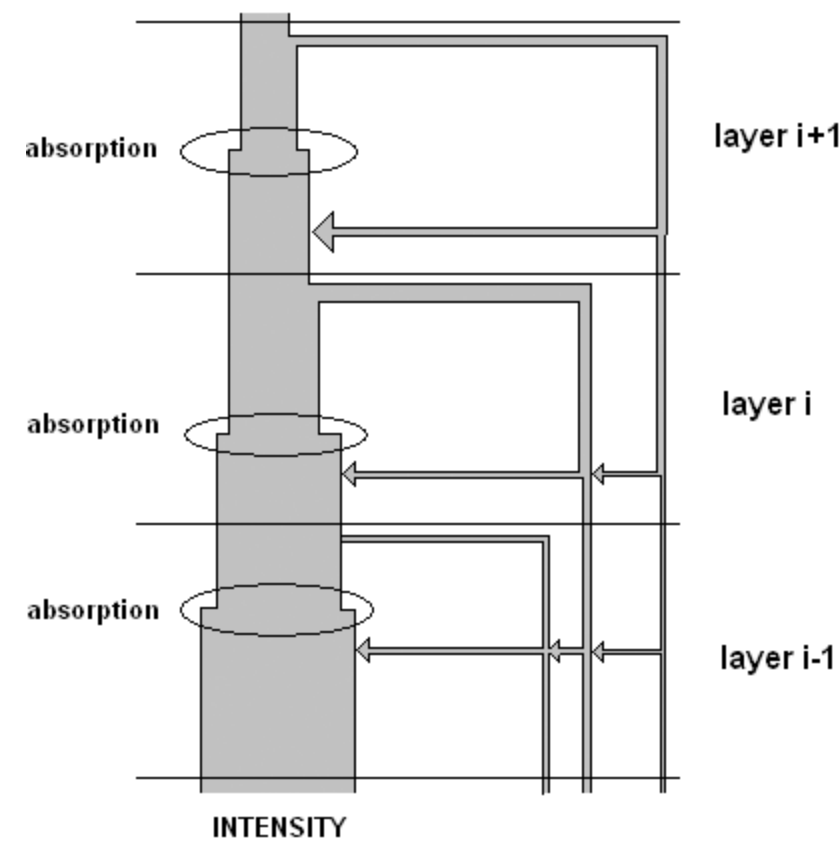

Fig. 1. The layer model of electron heating. For each layer the dissipation of RF energy is calculated by the Appleton-Lassen equation. Reflection at layer boundaries is also included in the present version of the heating model, although this effect is generally very small. A layer spacing of $1 \mathrm{~km}$ is used, as this is the resolution of the required input profiles produced by the SIC model (electron and atomic oxygen density) and the MSISE-90 atmosphere (neutral temperature, $\mathrm{N}_{2}$ and $\mathrm{O}_{2}$ profiles).

$4 \pi h_{0}^{2}$ (no absorption below the model altitudes) and the reflected irradiance is the sum of the reflections at layer boundaries:

$I_{\mathrm{refl}, i}=I_{i}\left(\frac{\operatorname{Re}\left(n_{i+1}-n_{i}\right)}{\operatorname{Re}\left(n_{i+1}+n_{i}\right)}\right)^{2}\left[\mathrm{Wm}^{-2}\right]$,

according to the Fresnel relations. As Fig. 1 suggests, the upward and downward irradiances should, in principle, be summed over an infinite number of reflections. Since the reflection is generally very small, only two iterations are used here.

The equilibrium electron temperature profile is calculated by equating the RF energy dissipation $Q_{i}$ to the losses in electron collisions with $\mathrm{N}_{2}, \mathrm{O}_{2}$ (elastic collisions, rotational excitation and vibrational excitation) and with atomic oxygen (elastic collisions, electronic excitation and finestructure transitions) as a function of temperature. Expressions given in Banks and Kockarts (1973) are used to parameterise the temperature dependence of these collisional losses.

\subsection{Riometer absorption calculation}

The estimate of riometer absorption $L$ for a given electron density profile is also based on the relations of electronneutral collision losses given in the work by Banks and

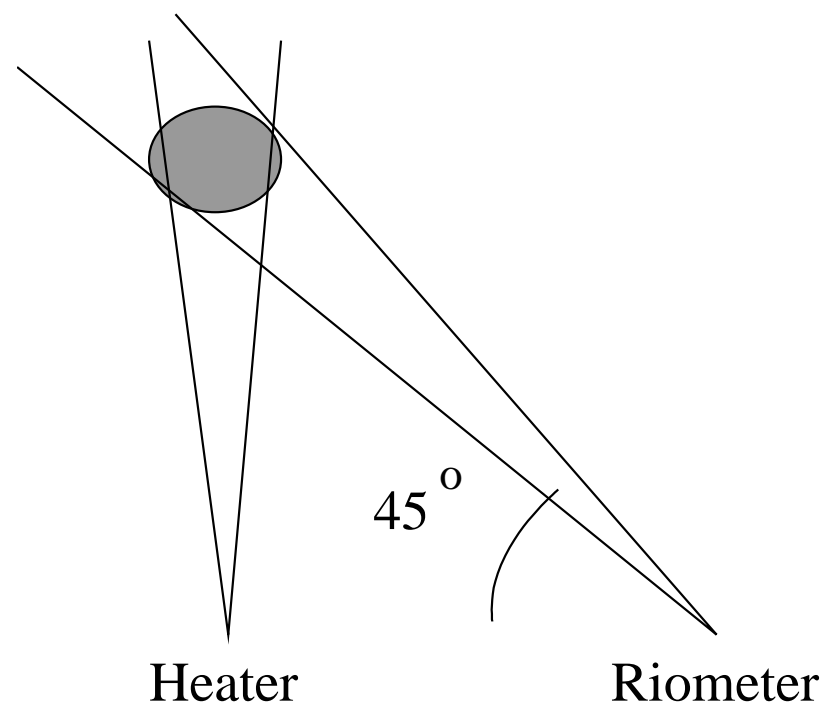

Fig. 2. The geometry of the riometer absorption calculation. An angle of $45^{\circ}$ between the heater and riometer beams is assumed, corresponding approximately to beam 9 of the IRIS riometer in Kilpisjärvi. We assume a perfect overlap.

Kockarts (1973). Using a formalism according to Sen and Wyller (1960) we calculate the differential absorption $\mathrm{d} L / \mathrm{d} h$ $[\mathrm{dB} / \mathrm{km}]$ of each model layer as a function of:

- The effective frequency $\nu_{\mathrm{e}}$ of electron collisions with $\mathrm{N}_{2}, \mathrm{O}_{2}, \mathrm{O}, \mathrm{H}$ and $\mathrm{He}$ at a given temperature;

- The riometer angular frequency $\omega_{\text {rio }}$;

- The electron gyrofrequency $\omega_{h}$ at altitude $h$ and latitude $\phi$, i.e.

$$
\omega_{h}=2 \pi \cdot 8.8 \cdot 10^{5} \sqrt{4-3 \cos ^{2} \phi}\left(\frac{R_{\text {earth }}}{R_{\text {earth }}+h}\right)^{3}\left[\mathrm{~s}^{-1}\right]
$$

using the pure dipole approximation of the magnetic field (which is used in the heating model as part of the Appleton-Lassen equation, as well).

To take into account the geometry of the riometer beam, the differential absorption $\mathrm{d} L / \mathrm{d} h$ is multiplied by the socalled effective obliquity factor, a function of the riometer beam width and zenith angle (Hargreaves and Detrick, 2002). All absorption estimates henceforth will be calculated for a geometry similar to beam 9 of the IRIS imaging riometer (Browne et al., 1995) at Kilpisjärvi $\left(69^{\circ} \mathrm{N}, 21^{\circ} \mathrm{E}\right)$ in northern Finland, which overlaps the heater volume in the entire altitude range of interest. The calculated effective obliquity factor of this beam is close to 1.42 at all altitudes, which means that we can simply apply the factor $\sqrt{2}$ expected for an infinitely narrow beam tilted by $45^{\circ}$, as shown in Fig. 2 . IRIS operates at a frequency of $38.2 \mathrm{MHz}$, which is therefore used in the calculations. 

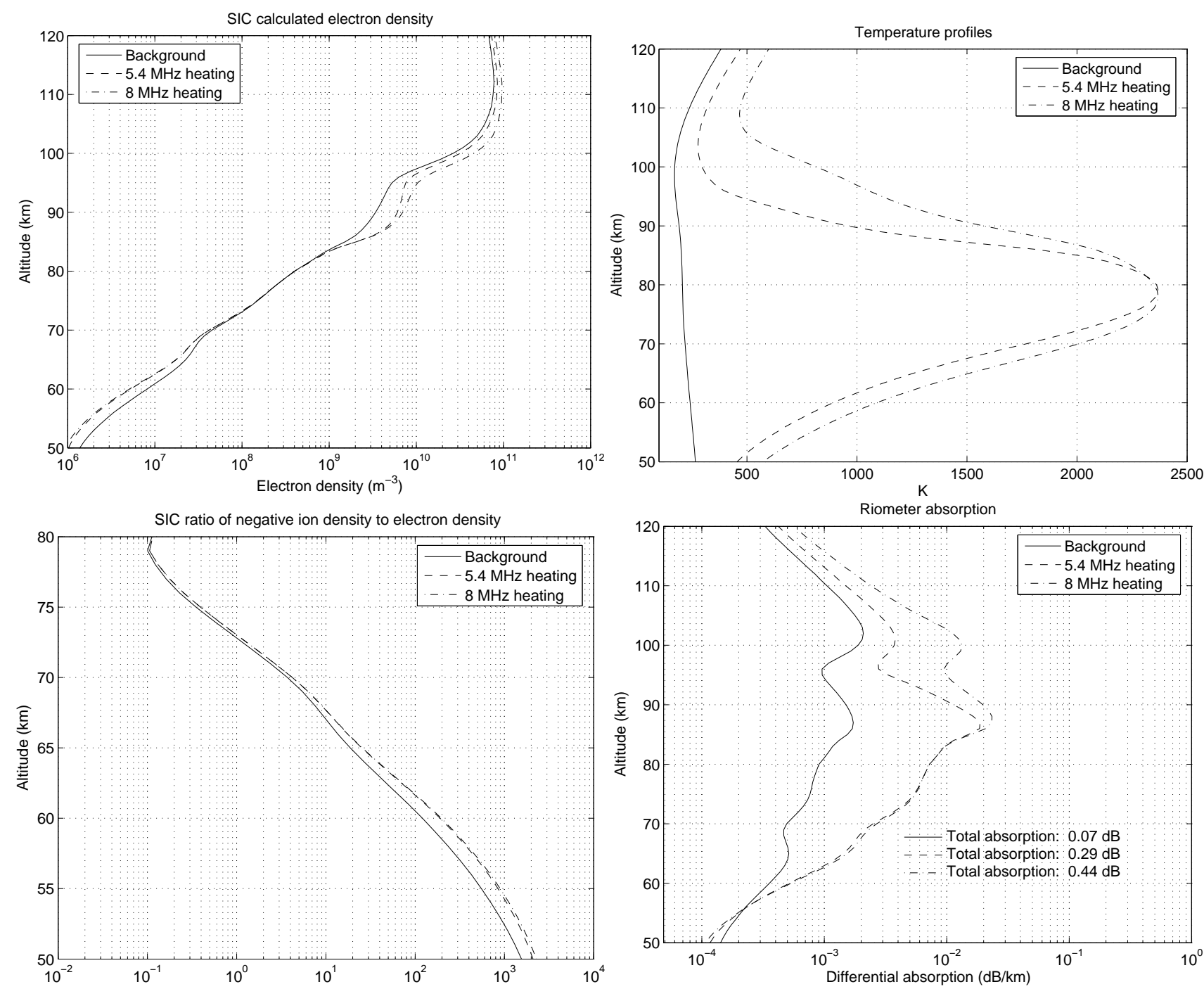

Fig. 3. The quiet-day noon case, altitude profiles at the end of the heating interval (12:55 UT) for the background run and the two heating cases of 0.6 GW ERP at 5.4 MHz and 1.2 GW ERP at $8 \mathrm{MHz}$. Plot 1: SIC modelled electron density; Plot 2: Electron temperatures; Plot 3: The ratio of negative ion density to electron density (NOTE: this is only shown for altitudes up to $80 \mathrm{~km}$ ); Plot 4: The calculated cosmic noise absorption at $38.2 \mathrm{MHz}$ as observed by a narrow riometer beam tilted by $45^{\circ}$.

\section{Model cases}

Initialisation of SIC for a new case requires the model to be run for several repeated one-day cycles with reasonable initial guess profiles until the results settle on a quasi-steady state. For this test case we chose the following parameters:

- Date close to equinox (1 April);

- $70^{\circ} \mathrm{N}$ latitude;

- $0^{\circ}$ longitude, for simplicity, to obtain LT=UT;

- Geomagnetically quiet conditions $\left(F_{10.7}=90, A_{p}=10\right)$ assumed for the MSISE-90 calculations;

- 36 positive ions, 25 negative ions and 11 neutrals, in total 72 variables;
- Altitude range $40-150 \mathrm{~km}$.

The heating model was configured for conditions similar to those of the EISCAT heater.

- Magnetic field calculated by the pure dipole approximation at the magnetic latitude of Troms $\varnothing\left(67^{\circ}\right)$;

- Transmission in the $\mathrm{x}$-mode at $5.423 \mathrm{MHz}$ with an ERP of $0.6 \mathrm{GW}$ (henceforth called the $5.4 \mathrm{MHz}$ case) and at $7.953 \mathrm{MHz}$ with an ERP of $1.2 \mathrm{GW}$ (called the $8 \mathrm{MHz}$ case). These values are for the largest antenna array of the EISCAT heater.

The SIC model was run in 5-minute intervals for $90 \mathrm{~min}$ after noon (intervals starting between 12:00-13:25 UTC). The solar zenith angle remains close to $66^{\circ}$ for this period. 

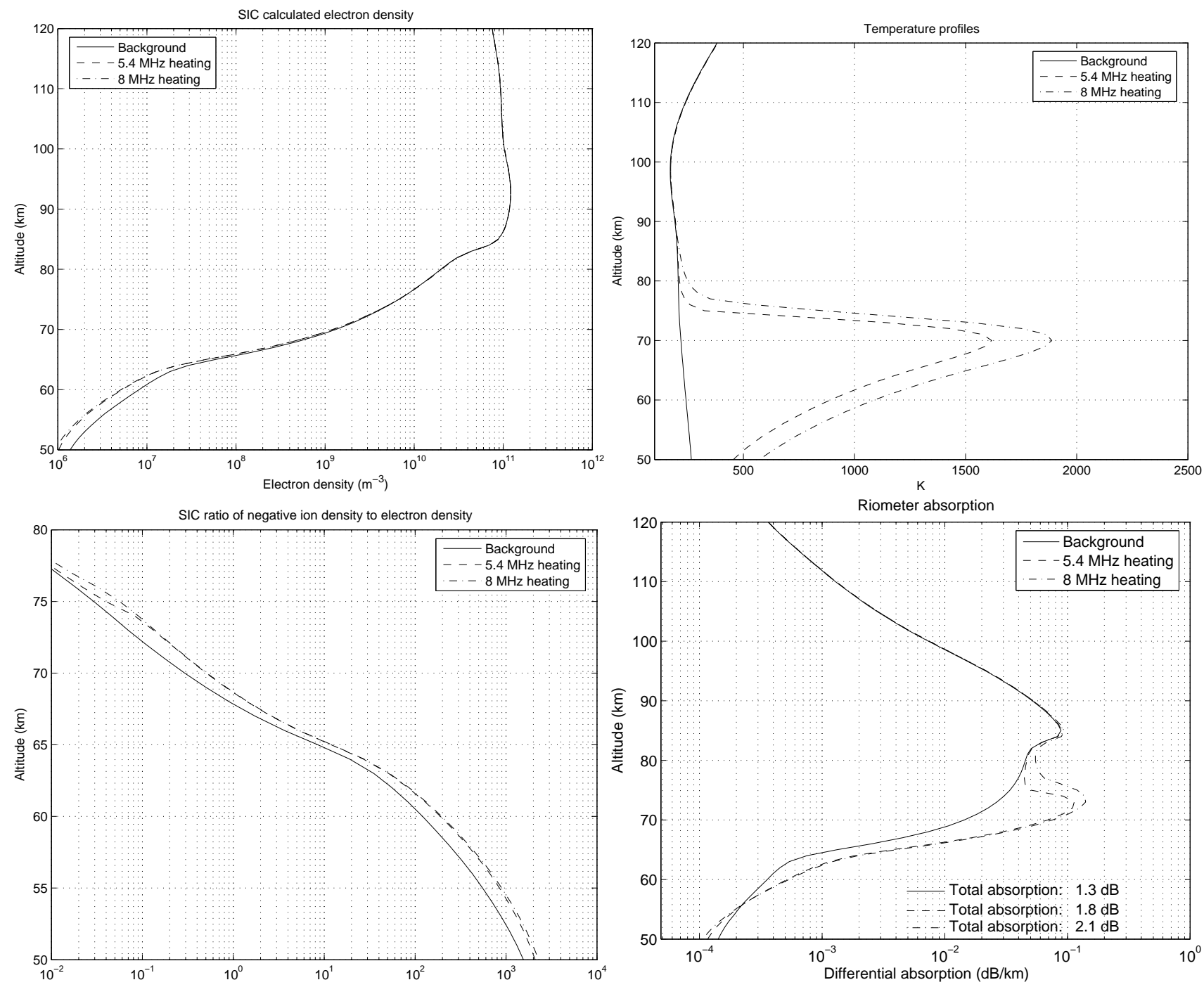

Fig. 4. The electron precipitation noon case, altitude profiles at the end of the heating interval (12:55 UT) for the background run and the two heating cases of $0.6 \mathrm{GW}$ ERP at 5.4 MHz and 1.2 GW ERP at $8 \mathrm{MHz}$. Plot 1: SIC modelled electron density; Plot 2: Electron temperatures; Plot 3: The ratio of negative ion density to electron density (NOTE: this is only shown for altitudes up to $80 \mathrm{~km}$ ); Plot 4: The calculated cosmic noise absorption at $38.2 \mathrm{MHz}$ as observed by a narrow riometer beam tilted by $45^{\circ}$.

Electron temperature profiles were set equal to the neutral (MSISE-90) temperatures except for $30 \mathrm{~min}$ during the intervals starting at 12:30-12:55, when the heating model was applied using SIC profiles of electron density and atomic oxygen from the previous intervals. The same calculations were also repeated for morning conditions (06:00-07:25 UT), an interval when the Sun rises from $85^{\circ}$ to $78^{\circ}$; however, only the total calculated cosmic noise absorption will be shown for the morning cases (Fig. 6).

The "heating-on" period of $30 \mathrm{~min}$ was selected to represent the longest possible time an air parcel is in the heater volume at typical zonal wind speeds. The following scenarios were assumed:

- Quiet day (where photons in the range from UV to Xrays are the only source of ionisation).
- Ionisation by photons as above, and precipitating electrons having a Maxwellian distribution with the characteristic energy $31 \mathrm{keV}$ and differential flux $0.8 \cdot 10^{9} \mathrm{~m}^{-2} \mathrm{sr}^{-1} \mathrm{~s}^{-1}$. This electron flux is estimated from a measurement on 28 November 1980 (Torkar et al., 1985) and gives an ionisation peak at $85 \mathrm{~km}$. Electron ionisation rates are calculated as in Rees (1989).

- Ionisation by photons and high energy protons. Proton ionisation rates are calculated according to Reid (1961). Proton flux data are from GOES satellite measurements on 29 October 2003 at 12:30 UT, to represent a large solar proton event. The ionisation rate in this case peaks at a low altitude, around $60 \mathrm{~km}$. 

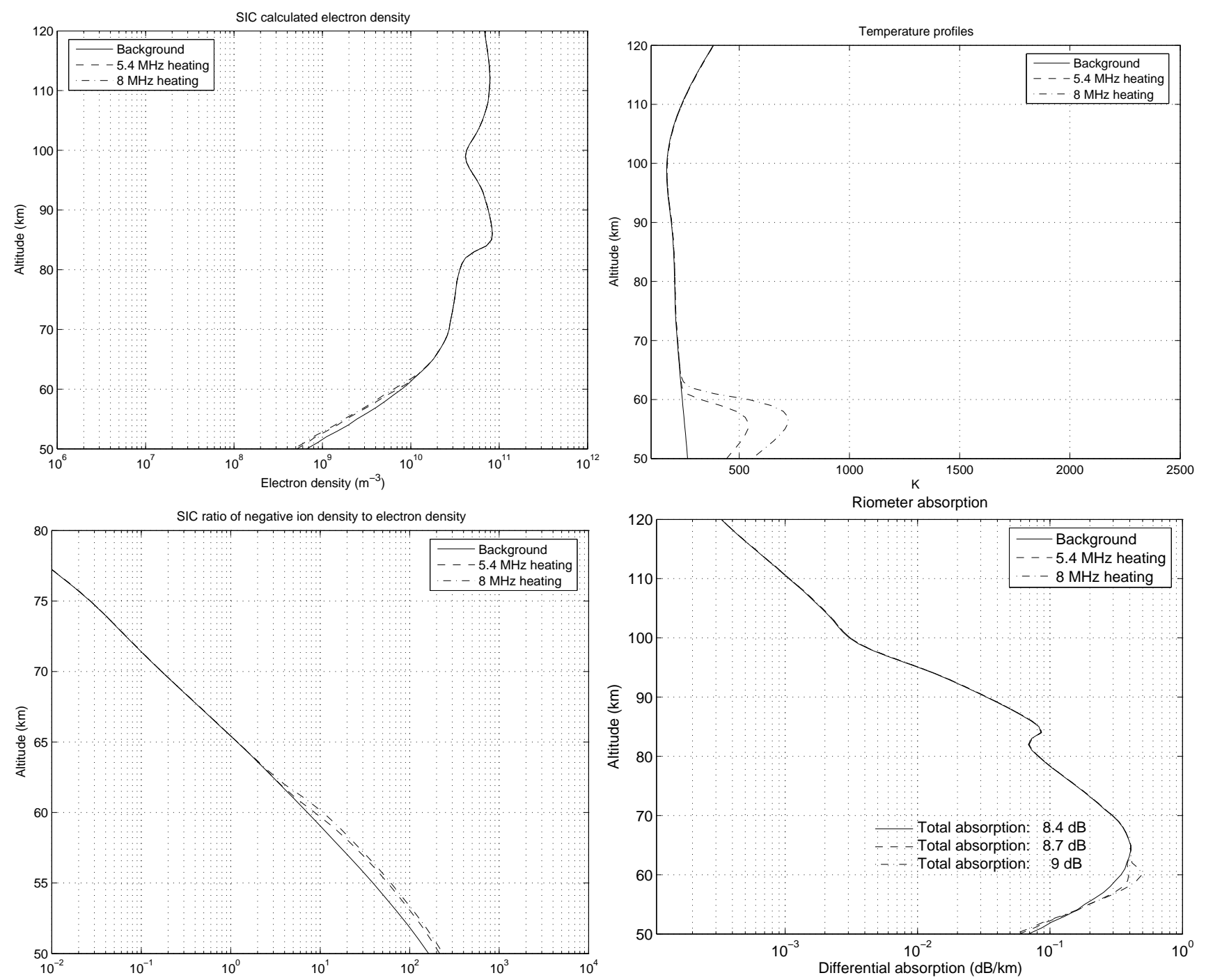

Fig. 5. The proton precipitation noon case, altitude profiles at the end of the heating interval (12:55 UT) for the background run and the two heating cases of $0.6 \mathrm{GW}$ ERP at 5.4 MHz and 1.2 GW ERP at $8 \mathrm{MHz}$. Plot 1: SIC modelled electron density; Plot 2: Electron temperatures; Plot 3: The ratio of negative ion density to electron density (NOTE: this is only shown for altitudes up to $80 \mathrm{~km}$ ); Plot 4: The calculated cosmic noise absorption at $38.2 \mathrm{MHz}$ as observed by a narrow riometer beam tilted by $45^{\circ}$.

\section{Results}

The first scenario shown is the background, 5.4-MHz and 8-MHz heating runs applied to the quiet background initial model atmosphere (Fig. 3). Due to the relatively low electron density below $100 \mathrm{~km}$, the absolute effect is small, whereas the electron temperature perturbation is very large, approximately $2500 \mathrm{~K}$, at its maximum around $80 \mathrm{~km}$. This gives rise to an estimated increase in riometer absorption of 0.2 $0.3 \mathrm{~dB}$. The total absorption was calculated by summing the differential absorption over the entire altitude range.

In the second scenario (Fig. 4), the ionisation by electron precipitation was switched on for the entire 1.5-h model run. This produces a significantly larger electron density between 70 and $100 \mathrm{~km}$. The maximum absorption of the heater wave, therefore, takes place at a lower altitude and the temperature increase is smaller, but the higher electron density causes a higher riometer absorption - the total absorption as summed over all altitudes being $1-1.5 \mathrm{~dB}$ - with a modelled increase of up to $0.8 \mathrm{~dB}$ during the heating period.

Finally, scenario 3 repeats the same calculations with proton precipitation according to the GOES measurements from 12:30 UT on 29 October 2003 (Fig. 5). The model does not include any rigidity effect (proton energy cutoff due to interaction with the magnetic field), so the estimate is a worst case, as seen in the high electron density and the small electron temperature enhancements. The heater wave in this scenario is now mainly absorbed below $65 \mathrm{~km}$ and the riometer absorption might be high, here above $8 \mathrm{~dB}$, which is sometimes also observed experimentally during solar proton 

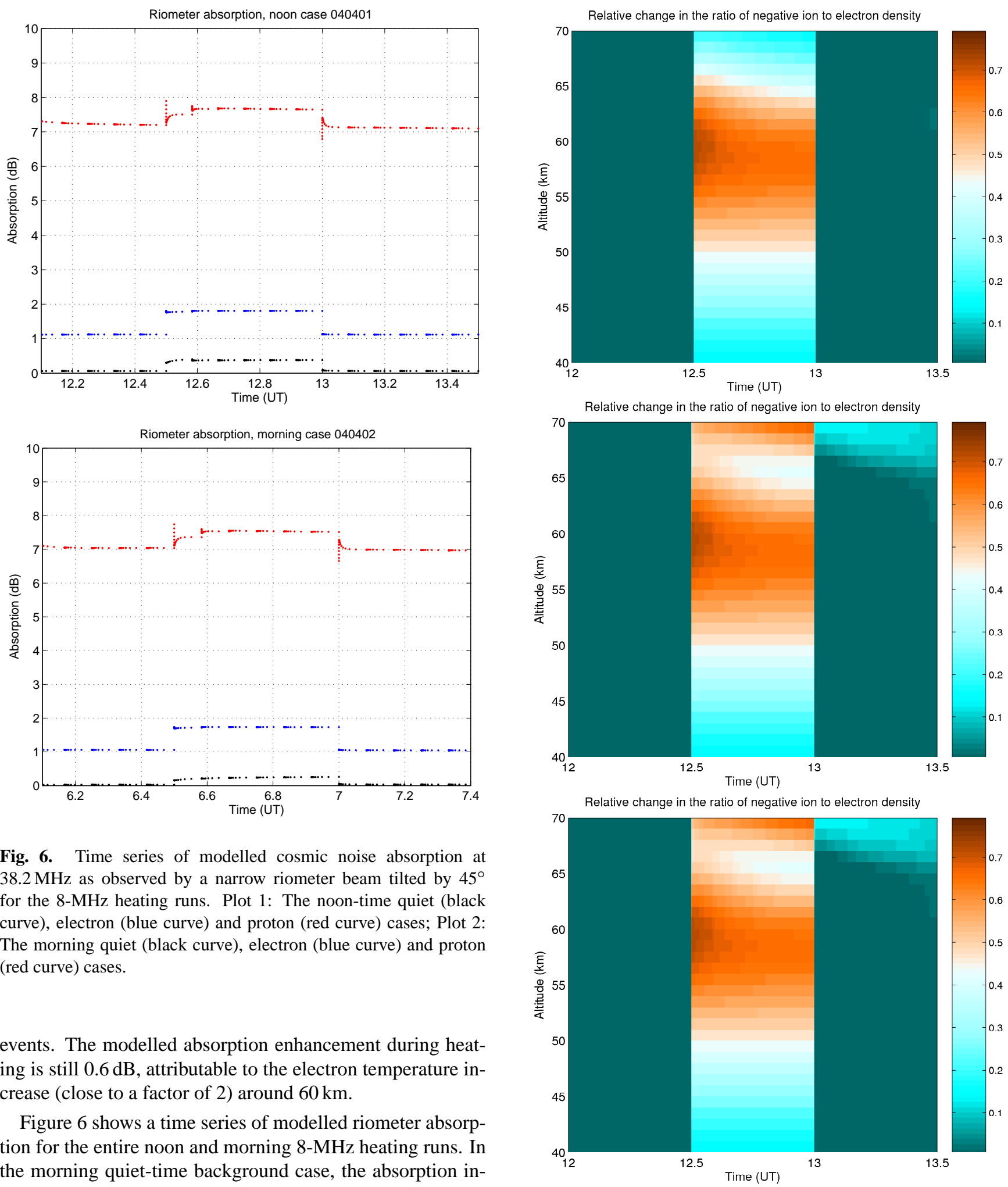

Fig. 6. Time series of modelled cosmic noise absorption at $38.2 \mathrm{MHz}$ as observed by a narrow riometer beam tilted by $45^{\circ}$ for the $8-\mathrm{MHz}$ heating runs. Plot 1: The noon-time quiet (black curve), electron (blue curve) and proton (red curve) cases; Plot 2: The morning quiet (black curve), electron (blue curve) and proton (red curve) cases.

events. The modelled absorption enhancement during heating is still $0.6 \mathrm{~dB}$, attributable to the electron temperature increase (close to a factor of 2) around $60 \mathrm{~km}$.

Figure 6 shows a time series of modelled riometer absorption for the entire noon and morning $8-\mathrm{MHz}$ heating runs. In the morning quiet-time background case, the absorption increases slowly from a very low level during the heating interval. In the proton cases it is evident that the 5-min resolution of the heating model runs cannot reproduce the actual rise in the absorption. More interesting is the almost instantaneous increase from the background level when there is a D region which is preconditioned by electron precipitation. The absorption subsequently stays almost constant during the heating interval.

Fig. 7. Time series of the relative change (between background and $8-\mathrm{MHz}$ heating noontime runs) in the ratios of negative ion to electron density. 1: The quiet-day case; 2 : The electron precipitation case; 3: The proton precipitation case. 
Figure 7 shows the relative change in the ratio of negative ions to electrons between the background and heating runs. These results confirm that an electron density depletion due to negative ion formation takes place. The exact rates of negative ion reactions will therefore affect the rates of electron density changes when the heater is switched on and off. The changes in negative ion densities also have a potential effect on minor neutral components. Therefore, in-situ measurements during heating would be a very interesting experiment to perform.

\section{Conclusions}

A number of test cases have been modelled and there is consistently an increase in cosmic noise absorption in the range $0.2-0.8 \mathrm{~dB}$ for the more realistic geomagnetic conditions. Although the electron density is somewhat reduced during the heating, due to production of negative ions, the fact that the increased electron temperatures cause enhanced electronneutral collision frequencies (and thus a larger absorption) in the heated volume is dominate in all modelled cases. However, runs for even larger proton fluxes (not shown here), resulting in a modelled background absorption (without heating) of up to $30 \mathrm{~dB}$, indicate that at very high ionisation rates the reduction of electron density due to negative ion production will dominate over the effect of increased collisional frequency. For such rare cases the effect of heating would be a decreased absorption.

The sensitivity of IRIS is approximately $0.05 \mathrm{~dB}$ (Detrick and Rosenberg, 1990), i.e. one order of magnitude higher than the expected modulation. Therefore, the predicted effect is detectable in this ideal case, where a good overlap between the heated volume and the riometer beam is assumed.

The rise and fall times of the modulated absorption have been shown above (Fig. 6) to be different for the different conditions modelled. In the proposed experiments a properly adapted combined SIC-heating model can be adjusted to reproduce the observed behaviour. In this way, we could improve the estimates of, for example, electron-to-neutral attachment rates, using the lower ionosphere as a natural laboratory.

Acknowledgements. EISCAT is an International Association supported by Finland (SA), France (CNRS), the Federal Republic of Germany (MPG), Japan (NIPR), Norway (NFR), Sweden (VR) and the United Kingdom (PPARC). IRIS is operated in cooperation between the University of Lancaster and SGO and its operation is funded by PPARC. CFE acknowledges financial support through the European Community's Human Potential Programme under contract HPRN-CT-2002-00216, Coupling of Atmospheric Layers. The authors thank T. Sergienko for discussions during the 31st Annual European Meeting on Atmospheric Studies by Optical Methods (31AM) and 1st International Riometer Workshop.

Topical Editor W. Kofmann thanks M. Rietveld and another referee for their help in evaluating this paper.

\section{References}

Banks, P. and Kockarts, G.: Aeronomy, Academic Press Inc., 1973.

Belikovich, V. V., Benediktov, E. A., and Terina, G. I.: Diagnostics of the lower ionosphere by the method of resonance scattering of radio waves, J. Atmos. Terr. Phys., 48, 1247-1254, 1986.

Belova, E. G., Pashin, A. B., and Lyatsky, W. B.: Passage of a powerful HF radio wave through the lower ionosphere as a function of initial electron density profiles, J. Atmos. Terr. Phys., 57, 265272, 1995.

Brändström, B. U. E., Leyser, T. B., Steen, Å., Rietveld, M. T., Gustavsson, B., Aso, T., and Ejiri, M.: Unambiguous evidence of HF pump-enhanced airglow at auroral latitudes, Geophys. Res. Lett., 26, 3561-3564, 1999.

Browne, S., Hargreaves, J. K., and Honary, B.: An Imaging Riometer for Ionospheric Studies, Electronics and Communication Engineering Journal, 7, 209-217, 1995.

Chilson, P. B., Belova, E., Rietveld, M. T., Kirkwood, S., and Hoppe, U.-P.: First artificially induced modulation of PMSE using the EISCAT heating facility, Geophys. Res. Lett., 27, 38013804, 2000.

Detrick, D. L. and Rosenberg, T. J.: A Phased-Array Radiowave Imager for Studies of Cosmic Noise Absorption, Radio Sci., 25, 325-338, 1990.

Hargreaves, J. K. and Detrick, D. L.: Application of polar cap absorption events for the calibration of riometer systems, Radio Sci., 37, 7.1-11, doi:10.1029/2001RS002465, 2002.

Hedin, A. E.: Extension of the MSIS Thermospheric Model into the Middle and Lower Atmosphere, J. Geophys. Res., 96, 1159$1172,1991$.

Kazil, J., Kopp, E., Chabrillat, S., and Bishop, J.: The University of Bern Ion Model: Time-dependent modeling of the ions in the mesosphere and lower thermosphere, J. Geophys. Res., 108, 4432, doi:10.1029/2002JD003024, 2003.

Kero, A., Bösinger, T., Pollari, P., Turunen, E., and Rietveld, M.: First EISCAT measurement of electron-gas temperature in the artificially heated D-region ionosphere, Ann. Geophys., 18, 12101215, 2000,

\section{SRef-ID: 1432-0576/ag/2000-18-1210.}

Kosch, M. J., Rietveld, M. T., Kavanagh, A. J., Davis, C., Yeoman, T. K., Honary, F., and Hagfors, T.: High-latitude pump-induced optical emissions for frequencies close to the third electron gyroharmonic, Geophys. Res. Lett., 29, 2112-2115, 2002a.

Kosch, M. J., Rietveld, M. T., Yeoman, T. K., Cierpka, K., and Hagfors, T.: The high-latitude artificial aurora of 21 February 1999: an analysis, Adv. Polar Upper Atmos. Res., 16, 1-12, 2002 b.

Mathews, J. D. and Bekeny, F. S.: The effect of negative ions on Thomson scattering in the presence of electron heating, Geophys. Res. Lett., 5, 925-927, 1978.

Minami, S., Nishino, M., Suzuki, Y., Sato, S., Tanikawa, T., Nakamura, Y., Wong, A. Y., and UCLA HIPAS Group: Ionospheric stimulation by high power radio waves, Adv. Space Res., 24, 997-1001, 1999.

Pashin, A. B., Belova, E. G., and Lyatsky, W. B.: Magnetic pulsation generation by a powerful ground-based modulated HF radio transmitter, J. Atmos. Terr. Phys., 57, 245-252, 1995.

Pashin, A. B., Kotikov, A. L., and Pudovkin, M. I.: Numerical simulation of auroral absorption in the artificially disturbed ionosphere, Geomagnetism and Aeronomy, 43, 59-62, 2003.

Rees, M. H.: Physics and Chemistry of the Upper Atmosphere, Cambridge University Press, Cambridge, UK, 1989. 
Reid, G. C.: A study of the enhanced ionization produced by solar protons during a polar cap absorbtion event, J. Geophys. Res., 66, 4071-4085, 1961.

Rietveld, M. T., Turunen, E., Matveinen, H., Goncharov, N. P., and Pollari, P.: Artificial periodic irregularities in the auroral ionosphere, Ann. Geophys., 14, 1437-1453, 1996,

SRef-ID: 1432-0576/ag/1996-14-1437.

Sen, H. K. and Wyller, A. A.: On the Generalization of the Appleton-Hartree Magnetoionic Formulas, J. Geophys. Res., 65, 3931-3950, 1960.

Shimazaki, T.: Minor Constituents in the Middle Atmosphere, no. 6 in Developments in Earth and Planetary Physics, D. Reidel Publishing Company, 1984.

Stubbe, P.: Review of ionospheric modification experiments at Tromsø, J. Atmos. Terr. Phys., 58, 349-368, 1996.

Torkar, K. M., Urban, A., Bjordal, J., Lundblad, J. Å., Søraas, F., Smith, L. G., Dumbs, A., Grandal, B., Ulwick, J. C., and Vancour, R. P.: Energy deposition rates by charged particles, J. Atmos. Terr. Phys., 47, 61-71, 1985.
Turunen, E.: Incoherent scatter radar contributions to high latitude D-region aeronomy, J. Atmos. Terr. Phys., 58, 707-725, 1996.

Turunen, E., Matveinen, H., Tolvanen, J., and Ranta, H.: STEP Handbook of Ionospheric Models, chap. D-Region Ion Chemistry Model, pp. 1-25, Scientific Committee on Solar-Terrestrial Physics, 1996.

Verronen, P.: Effects of energetic particle precipitation events on mesospheric neutral chemistry, no. 54 in Geofysikaalisia julkaisuja (Geophysical publications), Finnish meteorological institute, 2001.

Verronen, P., Turunen, E., Ulich, T., and Kyrölä, E.: Modelling the effects of the October 1989 solar proton event on mesospheric odd nitrogen using a detailed ion and neutral chemistry model, Ann. Geophys., 20, 1967-1976, 2002,

SRef-ID: 1432-0576/ag/2002-20-1967. 